\title{
FIND OUT THE PRINTING MATRIX OF THE NEAPOLITAN MARKS WITH INVERSE READINGS OF THE SURVEY DATA
}

\author{
L. Fregonese ${ }^{1}$, M. Gallo ${ }^{1}$, M. Pulcrano ${ }^{1}$, S. Scandurra ${ }^{1}$, F. Del Vecchio ${ }^{2}$ \\ ${ }^{1}$ Polytechnic of Milan, Dept. of Architecture, Built environment and Construction engineering (DABC), Campus Mantova, Italy \\ (luigi.fregonese, mara.gallo, margherita.pulcrano, simona.scandurra)@ polimi.it \\ ${ }^{2}$ freelance archaeologist, collaborator SABAP NA, Italy, francadelvecchio@libero.it
}

\section{Commission II}

KEY WORDS: Archaeological Survey, Marks, Stamps, Punch, 3D Modelling

\begin{abstract}
:
The paper presents the first results of the metric and geometric investigations carried out in the analysis of the stamps on Greek-Italic amphorae of Neapolitan production, found during the archaeological excavation of Piazza Nicola Amore, in Naples, Italy.

The experiments were carried out with a view to defining a methodological process useful on the one hand to document in a digital archive the three-dimensional morphology of the artefact under investigation, and on the other to allow new readings, through a manipulation of the data that goes beyond the physical limits of the artefact itself. In particular, the research presented here proposes the topological investigation for the identification of stamps obtained from the same punch and therefore the possibility of ideally reconstructing the printing matrix.

Since the stamps left by the punches on the amphorae are impressed at millimetric depths, the stamps are not always easy to read using traditional archaeological documentation methods. The research operations therefore began with the digitisation of a substantial number of finds by means of three-dimensional, reality-based surveys of sub-millimetre detail. Before proceeding with specific correspondence analyses, the archaeological classification based on the typological similarities of the marks was of great support.
\end{abstract}

\section{INTRODUCTION}

Three-dimensional surveys involve increasingly wide fields of investigation, favoured by a sudden technological advancement oriented towards highly accurate results and extremely userfriendly functional interfaces. Although the procedures for acquiring and processing the data are now quite consolidated, the objectives and peculiar characteristics of some objects require specific technical and methodological solutions. This is especially true in the close range where the object to be acquired is considerably small and therefore when attention to detail is essential and the resolution required is well below a millimetre. In the context of the research that we intend to present in this contribution, we want to address this type of circumstance. The application of reality-based survey technologies for the threedimensional documentation of fragments of archaeological artefacts, characterised by the presence of stamps, is investigated through a strongly multidisciplinary collaboration that sees, in particular, the involvement of knowledge relating to archaeology, architecture and geomatics.

The stamp, as is well known, is a mark imprinted on objects of an artisanal nature before they are baked or before they harden (amphorae, bricks, clay material, etc.). The imprinted part, and therefore deep in relation to the surface of the object, may be the part corresponding to the stamp itself or the negative part in relation to the mark; in the latter case, the sign representing the stamp appears in relief on the object. Their function, in any case, is to signal in some way the production origin of the object to which it is affixed, so much so that it is often composed of symbols, numbers or texts representing the craftsman, the workshop or bearing symbols representing precise historical moments, the year the object was made, etc. (Figure 1, Figure 2) The study of stamps is clearly very important in archaeology as it helps to construct the history of places and, often, to understand the events relating to production and trade. Usually, their

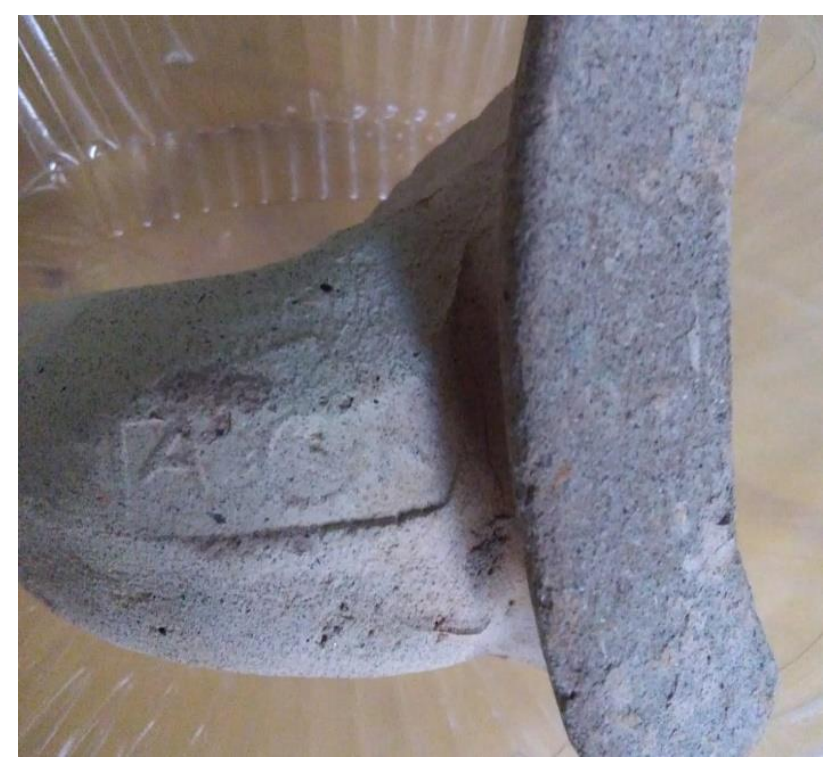

Figure 1: ГАP crown $\mathrm{N}$ stamp found on an MGS IV amphora fragment in the 2019 excavation campaign of the Piazza Nicola Amore area, Naples.

documentation and geometric analysis is done through the use of photographs that capture the object adjacent to a metric grid, often accompanied by contact surveys and ideal reproductions in two-dimensional graphs. It has been widely confirmed, also in the archaeological field, how interesting is the use of realitybased techniques for the digital reproduction of copies of the real object. (Antinozzi et al., 2021; Benedetti et al., 2011; Gonizzi Barsanti et al., 2013). In fact, this allows to virtualize the find, offering on the one hand the advantage of expanding the 


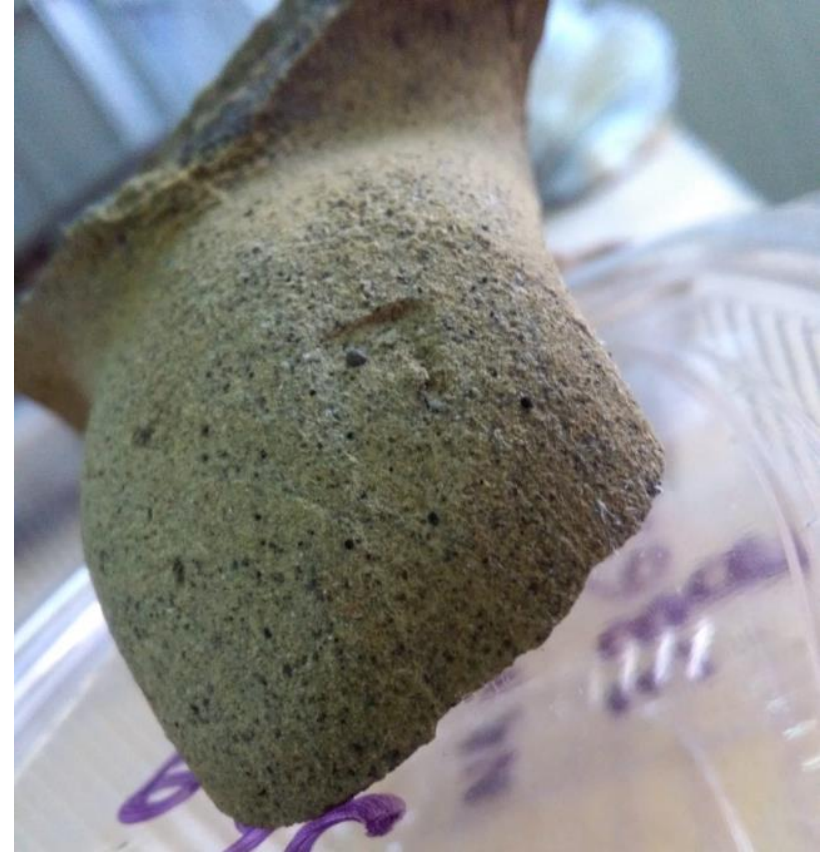

Figure 2: Photo of stamp on production waste. Some stamps remain poorly legible even following 3D survey.

boundaries of cultural dissemination and, on the other hand, to enjoy an extremely accurate data (Guidi et al., 2017). Moreover, digital transposition allows the free manipulation of the artefact for study and measurement purposes, without compromising its real features and limiting the risks related to accidental or unpredictable damage that could occur during direct analysis. Especially for those artefacts that are extremely fragile or considered particularly important due to their value or rarity, the use of indirect, non-invasive analysis is clearly advantageous.

The investigation presented here focuses on geomatic solutions for micro-reliefs (Bitelli and Girardi, 2010) and on 3D-printed physical reproductions of highly detailed objects. (Figure 3 )

The experiments specifically focused on the stamps that characterise the handles of numerous Greek-Italic amphorae found during the multi-year excavation campaign in Piazza Nicola Amore in Naples, Italy (Febbraro and Giampaola, 2012; Giampaola et al., 2014). As these marks were made with hand punches and were mostly found on artefacts with curvilinear surfaces, the various stamps are characterised by strong irregularities in the contours. This suggested that the research should be based on a preliminary sampling of finds, identifying by sight and with expert archaeological support, those characterised by the same type of stamp, and then proceeding with high-resolution three-dimensional acquisition activities. In this second phase, the data was reconstructed threedimensionally through point clouds and mesh, to support the activities of archaeological reading and analysis with new methods of documentation and communication of the recorded information.

\subsection{The Archaeological data: reading and cataloguing of finds}

During the works carried out for the realization of the Duomo station of the city's subway, during the excavation campaigns prior to 2019, a series of indicators suggested the presence of an area of Neapolitan production with a substantial number of objects datable between the late fourth and early third centuries
BC. Several MGS amphorae (mainly type IV) were found and the ГАР stamp on the handles was examined typologically, archaeometrically and epigraphically. The reading of the different stamps shows that ancient Greek letters ГAP are impressed in association with others - single or multiple (EY, M, $\mathrm{N}, \mathrm{ME}, \mathrm{MEK}$, etc.) - and the crown symbol. La corona è riferibile all'antica lampàs che sfilava durante le cerimonie sacre in onore della sirena Partenope (le Lampadodromie), e ne suggerisce una produzione direttamente in situ.

The most recent discovery, and the consequent stratigraphic excavation, of a kiln active between the end of the 4th and the beginning of the 3rd century B.C. confirms and enriches the information on the production plant. The discovery of MGS- GR ITA IV amphorae, many of which were marked and some of which were production waste, suggests that the kiln was mainly dedicated to their production, probably in association with other clay materials (loutheria, bricks, loom weights).

The next chronological phase, at the beginning of the 3rd century B.C., contains very interesting stamps. Many of them are related to the production of greek-italic amphorae of the type MGS- GR ITA Va, with the stamp EY EENOY, often combined with API, in different variants, also in production waste. They were probably made in an artisan atelier active in the Hellenistic period, which evidently attests to a continuity of production of Greek-Italic amphorae in loco.

The stamp until now was loosely associated with the Gulf of Naples area, perhaps Ischia (Olcese, 2010. p.123), but not mineralogically with the Santa Restituta atelier. It is probably connectable to the $\Gamma$ AP crown EY stamp group (EY of the ГAP crown EY stamp is comparable to EY- छENOY, and perhaps, the repeating AR nexus also ties the two stamps).

The remains of the wine amphorae and the relative stamps to be subjected to the different phases of the operational experimentation were typologically catalogued and classified on the basis of an autopsy analysis of the stamps. A selection was then made of those considered most interesting for the purposes of this research, for their importance and for their morphological and topological characteristics. These stamps are mainly found in the area of Piazza Nicola Amore, impressed on the Greek-Italic amphorae of type MGS IV which bear the variants of the matrix $\Gamma A P$ with crown and letters, in different combinations and writing patterns.

Other chosen stamps, XAPME $\Omega$ and XAP, although less frequent, but with production indicators are highly attested in Piazza Nicola Amore; MAMARKOY can be referred almost exclusively to the production area of Via dei Fiorentini, behind the ancient port of Neapoli; TPEBI $\Omega$ is most likely related to production on the island of Ischia. They have been chosen because they are considered to be of equal importance for the definition of the production and circulation of the specific type of amphorae is much studied both in the production sites on the mainland and along the distribution routes, especially by sea, as

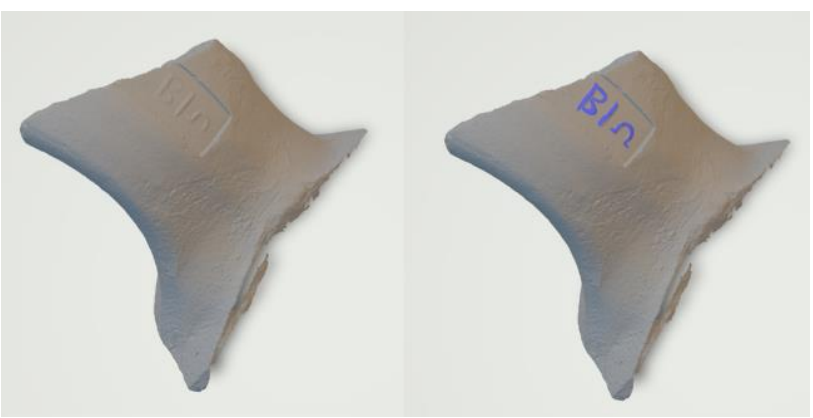

Figure 3: 3D survey and highlighting of stamp (TRE)BI $\Omega$, No.85. 


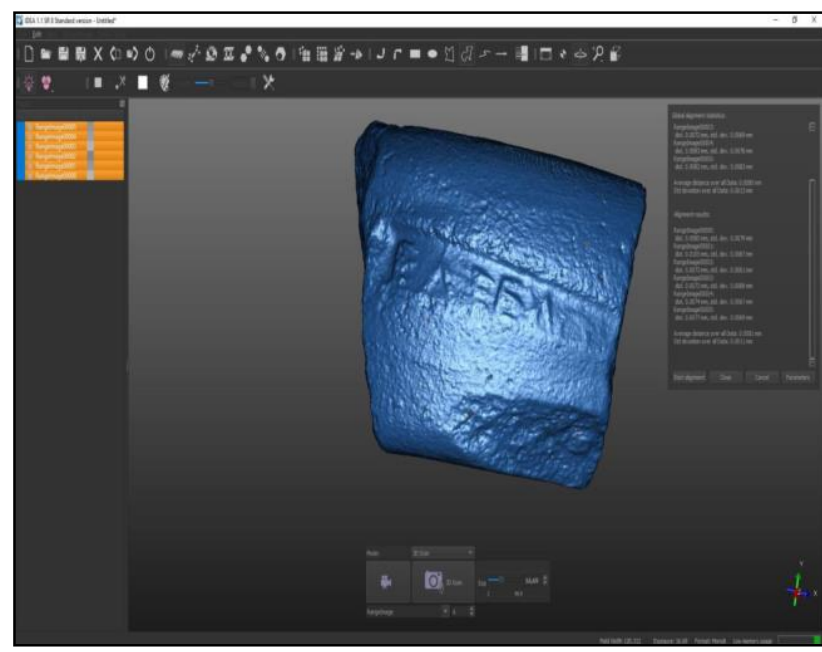

Figure 4: 3D laser survey of mark No. 63. Global registration for the alignment of the six acquisitions in IDEA software.

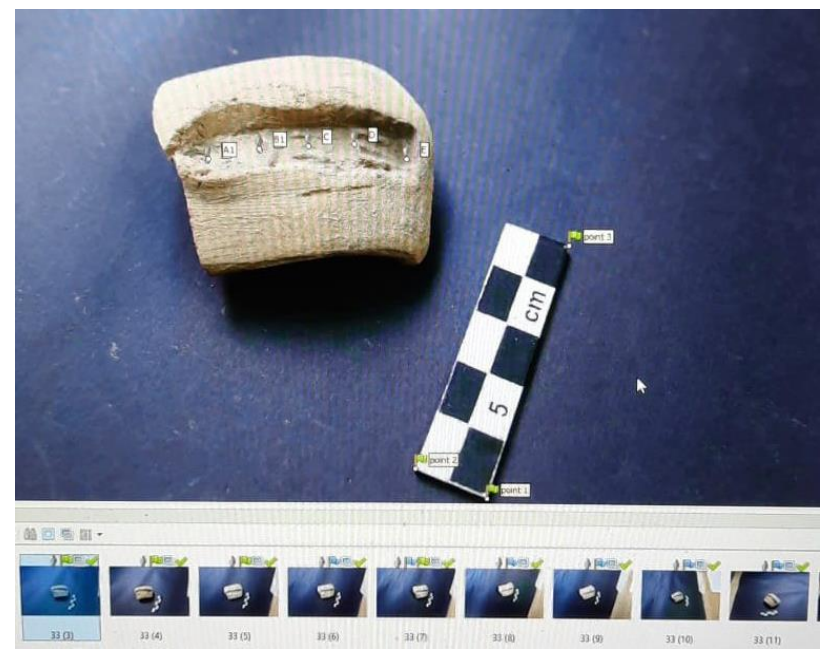

Figure 5: Photogrammetric survey of stamp No. 33. The dimensions were checked with the metric bar.

they were the main cargo of numerous wrecks in the relevant chronological range.

Although many of the stamps on the MGS IV amphorae had already emerged in previous excavation campaigns and are already published (Pugliese, 2014), from an archaeological point of view the experimentation conducted poses new perspectives and interesting insights, especially in the possibility of making more accurate comparisons between apparently similar signs. However, new stamps have been attested above all in relation to the equipment installed in the first half of the III century B.C. in the area of the kiln, by now disused. These are EYXENOY stamps, in different combinations and variants, which until now could not be associated with certainty with Neapolitan production. The quantity of the finds and the variety of the punches confirm their local provenance, enriching the epigraphic panorama of Neapolitan amphorae of Greek-Italic type. The different production sites identified and the punctual analyses on the clays support the hypothesis - in part confirming it - of the presence of real ateliers dedicated and linked to single personages, in rare cases arranged for the circulation of personal punches in the same geographical area (Giampaola et al., 2020). Their collection and reading brings important news for the reconstruction of the history of Neapolis and beyond.
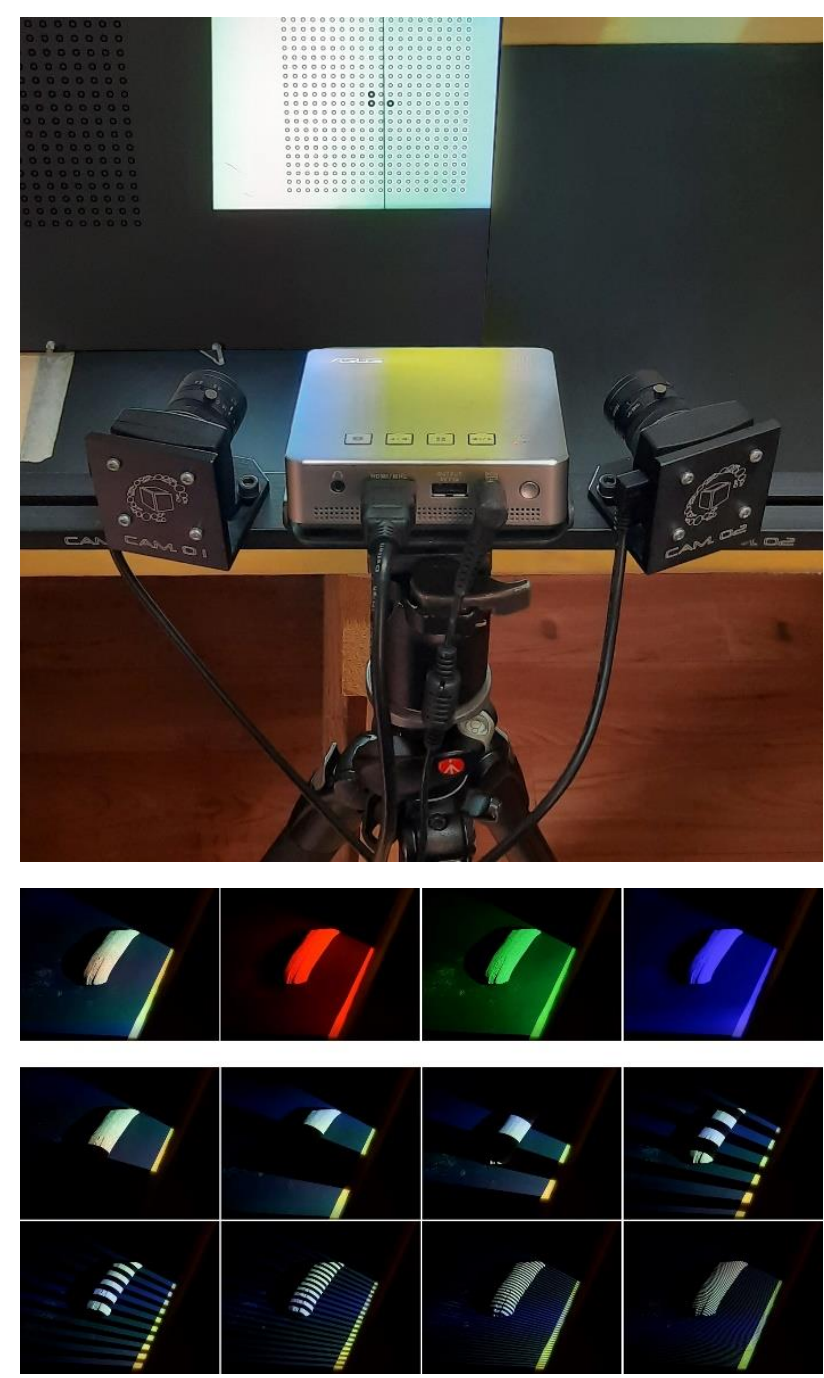

Figure 6: SCAN in a BOX, calibration of the instrument and projection of the light pattern on the stamp detected.

\section{THE INTEGRATION OF REALITY-BASED SYSTEMS FOR THE 3D ACQUISITIONS OF STAMPS}

For the three-dimensional metric survey and the recording of the morpho-dimensional characteristics of the catalogued stamps, it was decided to use reality-based acquisition methods, integrating laser scanner technologies and digital photogrammetry techniques.

The SCAN in a BOX structured light scanner was used for the laser survey. This system, as is well known, requires a preliminary phase of configuration and calibration of the optics in order to identify the acquisition parameters of the cameras (position, orientation, focus and exposure) in relation to the field of view of the instrument, to the size and position of the objects to be detected and to the geometric quality to be returned in the digital model. (Figure 4, Figure 5, Figure 6)

For the survey of the amphora finds it was decided to set a field of view of 100x $80 \mathrm{~mm}$ and, consequently, the pattern used as a reference to proceed with this first operative phase has dimensions of $100 \times 100 \mathrm{~mm}$ and a $5 \mathrm{~mm}$ pitch between the graphic elements that compose it. These settings also determined the maximum acquisition distance of $200 \mathrm{~mm}$. 
Since the stamp is often affixed to amphora handles, the surface of the find is curvilinear and this does not allow a complete acquisition with a single scan. Therefore, 2 to 12 scans were made for each of the analysed stamps, depending on the size of the object. The union of the different scanning points took place at the same time as the acquisition phases by identifying homologous points in the workspace of the proprietary software associated with the laser scanner - IDEA the software for 3D Scanning -. In this way it was possible to verify the presence of any gaps in the scanning in real time and to obtain a model as complete as possible of the various finds.

The raw alignments were followed by further phases of data processing, aimed in particular at optimising the registration of the acquisitions with automated global registration processes, cleaning the point model of noise and portions considered insignificant and, finally, creating polygonal meshes useful for the subsequent phases of analysis.

Although the colour data was acquired with the SCAN in a BOX, it was decided not to associate the RGB data with the laser model, so that it would be possible to analyse the shapes of the object without the chromatic transitions of the photographic data interfering with the interpretation of such minute shapes.

As for the image-based surveys, on the other hand, the traditional digital photogrammetry pipeline was used, proceeding with the acquisition of photographic frames from which the threedimensional data was returned. For the acquisition, a reflex camera equipped with macro optics and placed on a tripod was used, so that the millimetric variations of the characteristic surfaces of the stamp could be acquired and the disturbance minimised. A dataset of approximately 20 images was required for each fragment and processed in the SfM Agisoft Metashape software. Also in this case the polygonal models were produced and, for a comparison in readability between the different acquisition techniques, the model was completed with photographic textures. In this case, the colour information was also retained as the brightness and shadows recorded in the different frames were manipulated to accentuate surface variations.

Although the products obtained from the reality-based surveys both aim at high-resolution digital restitution, they produce point clouds that are structurally different from each other, the comparison of which was necessary in order to obtain more accurate readings of the stamps. They were set up by superimposing the models on the basis of equivalent point pairs identified in the CloudCompare software. During registration in the same relative reference system, the range-based point cloud was set as the reference on which to rotate the image-based one. The decision to proceed with a similar approach, i.e. to consider the two point clouds as layers that are part of the same design and, therefore, to integrate them while keeping the single data separate, was dictated by the prefiguration of the subsequent phases of the investigation. For these, in fact, an overlapping reading of the models was considered more useful, avoiding that the accuracy of the data be influenced in the metric specificities. In this way, the two models can be viewed and interrogated individually and together as required. (Figure 7)

\section{THE COMPARISON BETWEEN 3D MODELS}

Observing the same stamp on different amphorae, the inconsistencies arising from the different pressure exerted by the punch or the state of preservation of the matrix used clearly emerge. This has led to the decision to detect several times, on different finds, the same type of stamp, in order to compare them with each other in digital space. For the comparison, it was necessary to take into account the fact that, although originally

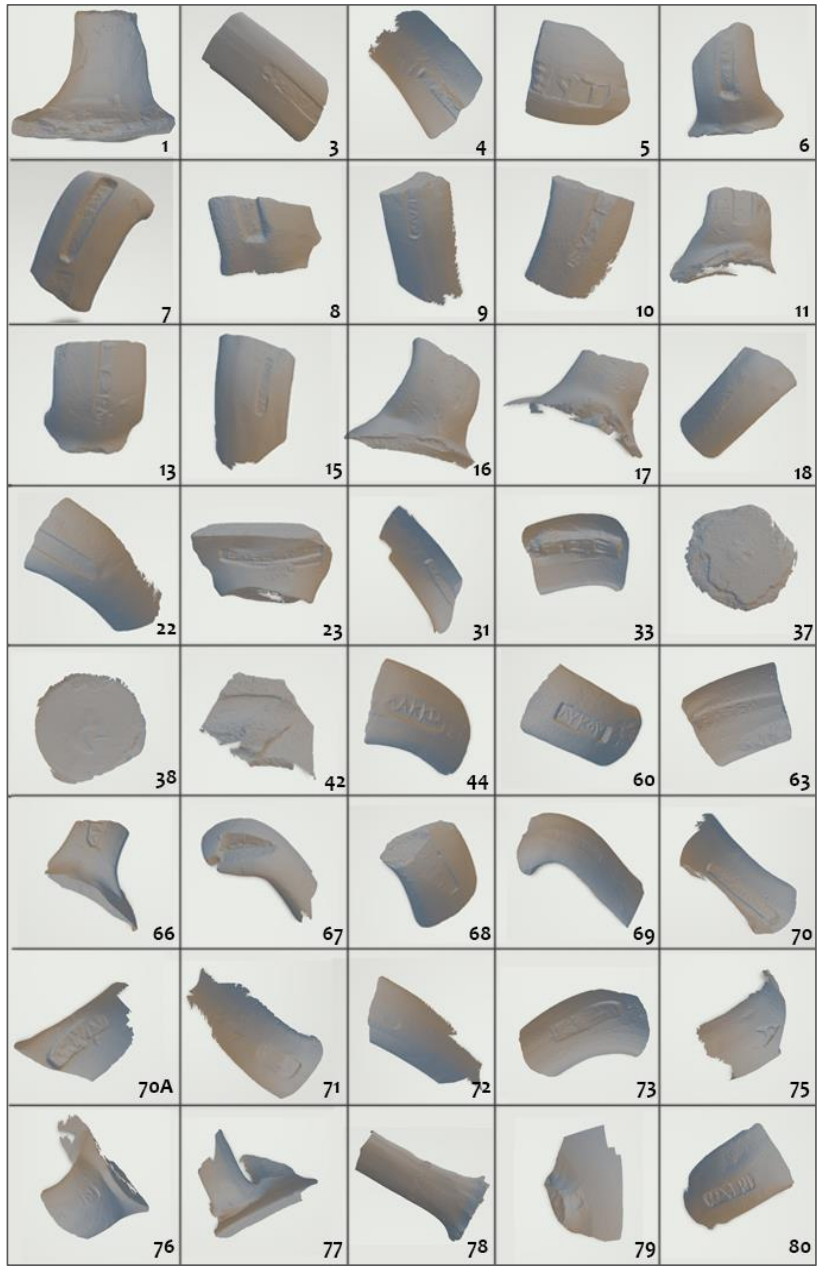

Figure 7: Portion of the stamps acquired with structured light laser scanner.

developed on a plane, the punch impressed the stamp on different surfaces due to curvature.

In three-dimensional modeling software it is possible to associate a 3D surface with its corresponding flat surface only and exclusively when the former is a developable surface. In fact, Smash or Squish operations are possible which, according to different geometric rules, make the comparison between the 3D and the base plate used for its generation immediate.

In the case of the stamps, however, the surface cannot be considered developable because it should, on the one hand, stretch to zero the deformation generated by the curvilinear surface of the amphora and, on the other hand, maintain the differences in the protrusions and cavities that characterise the signs of the stamp itself.

Another important consideration concerned the working dimensions for the analysis of the stamp itself. In the context of the finds analysed, it was found that the various punches generated a groove on the surfaces that was on the whole between $0.5 \mathrm{~mm}$ and $5 \mathrm{~mm}$ deep. The marks relating to the letters or symbols representing the specific stamp are in turn $0.5 \mathrm{~mm}$ to 2.5 $\mathrm{mm}$ more prominent or deeper.

These considerations have led to the application of two different types of procedures for comparison:

- A three-dimensional mesh-to-mesh comparison for similar curves. In this case, ranges in the divergence values were established a priori so that the curve was comparable. 


\begin{abstract}
MARK TYPE/NUMBER $\quad$ EYEENOY, 69
PORTION OF MESH

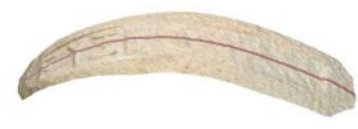

SECTION OF MESH

CURVE

DISCRETIZATION

PLANAR VIEW stamp.

- A two-dimensional comparison performed on 2D projections of the 3D data. In this case, too, a certain margin of error had to be accepted, since the projection of a three-dimensional surface onto a plane inevitably involves deficiencies in at least one of the constituent characteristics (shape, area, angles, distance).
\end{abstract}

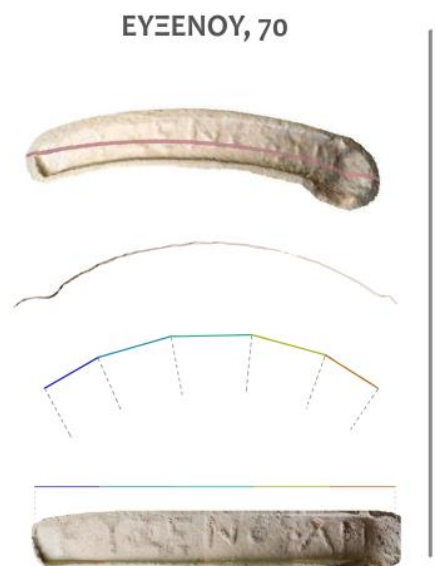

n.69

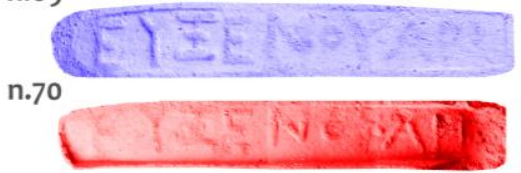

COMPARISON

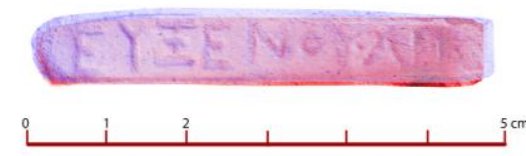

Figure 8: Discretization of marks EY $\Xi E N O Y$ No. 69 and No. 70. The overlap of the final images shows a correspondence of the

The mesh-to-mesh comparison took place directly in the compare cloud software.

The datasets of the individual scans were compared two by two starting with the identification of homologous points - from a minimum number of 3 to a maximum of 9. A rigid rototranslation was applied to each dataset to minimise the average distance between the two sets of data. As was to be expected, the distance values calculated in each case showed a maximum fit in the vicinity of points located on portions of the surface whose curvature is so minimal that they can approximate a plane. In this respect it was extremely advantageous to work on objects of such small dimensions, with better results being obtained for vignettes that were less extensive in length.

Of all the stamps acquired, only four responded effectively to this comparison, with two of them matching.

The two-dimensional comparison was carried out using flat projections of the vignettes.

For the construction of the two-dimensional image, it was decided to analyse the geometry of the curvature of the portion of the amphora affected by the stamp. The 3D model was then sectioned longitudinally to the stamp, extracting the corresponding polyline. The polyline was analysed in CAD in order to define its curvature centres and the possible discretization into a series of segments. The segments identified were used to establish the different projection planes, one for each of the individual portions.

The overall image consisting of the union of the different projected faces was used for comparison.

From the comparisons it was interesting not only to find matches but also to recognise the existence of different punches for stamps of the same type.

Equally interesting was the possibility of identifying matches between stamps that were only partially visible or whose fragment was incomplete: this made it possible to establish a wider spread of the type investigated. (Figure 8)

\section{THE DEFINITION OF THE IDEAL MATRIX}

From the comparisons it was possible to identify stamps generated by the same punch.

In the case of those stamps for which matches were found, the three-dimensional data were segmented into individual letters/symbols or portions thereof to make them superimposable on the two-dimensional image obtained for the second type of comparison. Only point clouds were used for this operation, as each stamp of the same punch appears to consist of more readable and less readable parts.

After choosing the parts of each stamp that were visibly better preserved, the cloud portions were merged, generating the basis for the restitution of a stamp that ideally corresponds to the flat trace of the original punch, to be transformed into an overall mesh.

The transformation of the point model into a surface model served to reproduce the material continuity of the object. In this research, this step was considered fundamental so that, starting from the digitally recreated stamp, the punch that generated it could be reconstructed in negative.

In order to reproduce the punch, NURBS modelling techniques were indispensable, in order to simulate the forms of the graphic and textual symbols that emerged from the analysis of the stamp. The data was then imported into Rhinoceros software for machining.

The objective of the research is the prototyping of the punch by means of 3D reprinting in fused deposition modelling (FDM) with PLA type thermoplastics, a phase of the work that is still in progress.

\section{RESULTS}

Until now, the epigraphic work was based on the autopsy reading of the artifacts, not always immediately readable due to the state of preservation, and it made use of detailed photos or contact surveys. The opportunity of a 3D survey, with the instrumentation and the scientific attention given, has allowed us to make use of a three-dimensional iconographic base, certainly easier, precise in scale ratios, totally manipulable in a digital environment and inclinable according to the best reading angle. This was able to not only confirm, but also foreshadow a number of potential analyses otherwise not immediately possible. 
n. 63
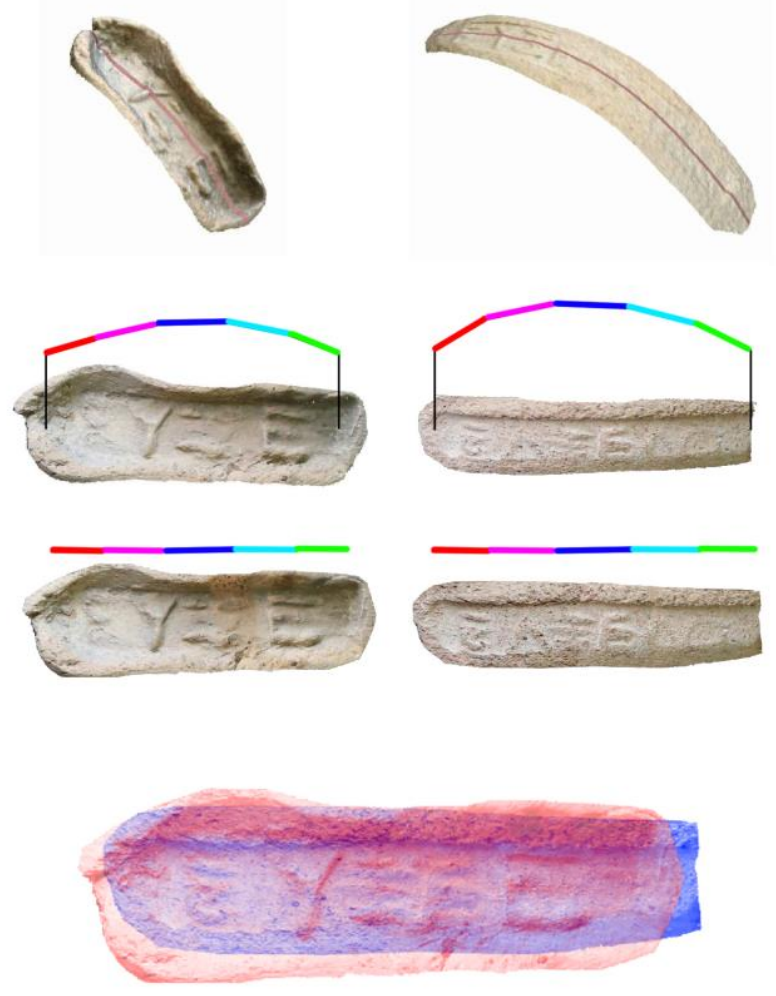

Figure 9: Comparison between stamps No. 63 and No. 33: they are of the same type but derive from different punches.

\section{GAR corona $M$}

n. 15

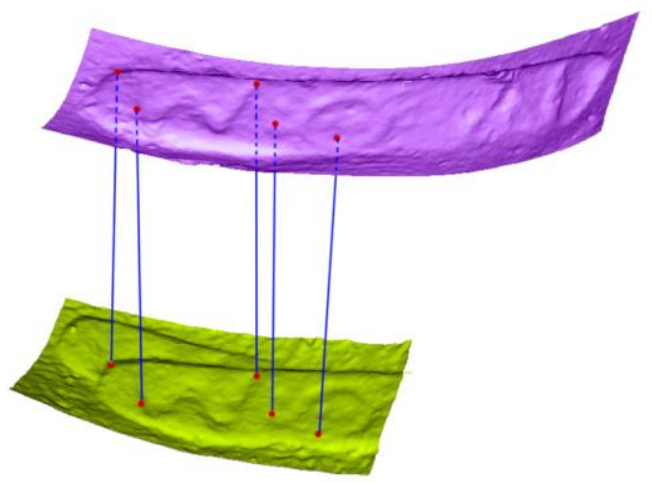

3D COMPARISON

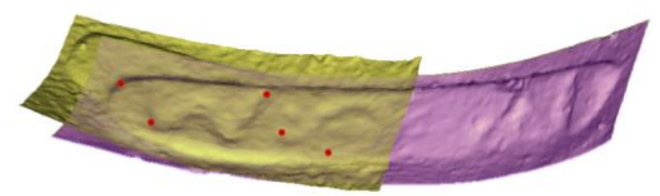

Figure 10: Comparison of GAR crown M No. 15 and No. 17. Although No. 17 is only a fragment, the correspondence with No. 15 confirms that it belongs to the same stamp.
The work of real 3D casts, which can also be printed threedimensionally and which allow the perfect superimposition of the stamps of the same punch, down to the smallest details and measurements (e.g. stamps No. 15 and No. 17 for the type ГАP crown $\mathrm{M}$, perfectly attributable and meltable in reading, even if only partially preserved), has assisted traditional reading methods. (Figure 10)

Moreover, an innovative and rapid technique (almost 30\% of the stamps under examination were scanned in a single acquisition campaign), combined with careful, accurate and precise documentation, especially for future editing and/or iconographic collection, ensured greater certainty in the interpretation of the epigraphic sources on the stamps under examination. Autopsy readings have been confirmed and clarified. (Figure 9) The few illegible specimens, which remain illegible even after the use of the 3D laser scanner (Figure 2), are not included in the analysis; unfortunately, these are often related to rejects that would prove to be decisive for a definitive confirmation of the productions, so far certainly confirmed by the high frequency of a stamp and its variants. Very often, in the case of Naples, they are suggestively linked to monetary issues, recalled by symbols such as the torch or, perhaps, by abbreviations referring to the anthroponyms of coin and stamp issues.

\section{CONCLUSIONS}

The multidisciplinary nature of the investigation broadens the boundaries of the documentation of the archaeological find, leading to models of varying degrees of accuracy and use, while at the same time allowing the original object to be preserved. This process proposes a different interpretation key to complete the knowledge of local handicrafts. Focusing, in particular, on the greek-italic amphorae MGS IV, starting from the variants with the famous stamp with the crown in different combinations and MGS V with the new stamps is an indicator of production and enriches the panorama of epigraphic evidence on Neapolitan amphorae, supporting with new data the reconstruction of the history of Neapolis.

\section{ACKNOWLEDGEMENTS}

We would like to thank the superintendent of the City of Naples, archaeologist Luigi La Rocca, and officials Dr. Daniela Giampaola and Dr. Giuliana Boenzi for facilitating and encouraging the study and publication of the contexts presented. In addition, our thanks go to the entire team, coordinated by Dr. Beatrice Roncella, who worked on the analysis of the complex and extraordinary archaeological evidence, from which the analyzed data emerge. The archaeological research is related to the works for the construction of the Duomo Station of the Naples Metro, in Piazza Nicola Amore.

The archaeologists M. Ascione, M. De Filippo, F. Del Vecchio, A. Esposito, R. Laurenza, the architects of Entasis studio and the Polytechnic of Milan collaborated to the excavation activities.

Engineer F. Fassi of the Polytechnic of Milan collaborated in the survey of the stamps discussed in this paper.

\section{REFERENCES}

Antinozzi, S., Ronchi, D., Fiorillo, F., Barba, S., 2021. 3Dino: Configuration for a Micro-Photogrammetric Survey - Applying Dino-Lite microscope for the digitalization of a cuneiform tablet. Applying Dino-Lite microscope for the digitalization of a 
cuneiform tablet. In 39th eCAADe Conference, Vol. 2, University of Novi Sad, Novi Sad, Serbia, pp. 211-222.

Benedetti, B., Gaiani, M., Remondino, F. (a cura di), 2011. Modelli digitali $3 D$ in archeologia: il caso di Pompei. Scuola Normale Superiore press.

Bitelli, G., Girardi, F., 2010. Problematiche nel rilievo e modellazione tridimensionale di oggetti di piccole dimensioni nel campo dei Beni Culturali. Atti $14^{\circ}$ Conferenza Nazionale ASITA, pp. 285-290.

Febbraro, S., Giampaola, D., 2012. Ceramiche comuni e vernici nere dal quartiere artigianale di Piazza Nicola Amore a Napoli. In FACEM. (www.facem.at/project-papers.php)

Giampaola, D., Febbraro, S., Pugliese, L., 2020. L’artigianato ceramico a Neapolis in età ellenistica. Topografia delle produzioni. SC.Ant.

Giampaola, D., Febbraro S., De Bonis, A., Guarino, V., Morra, V., Grifa, C., Langella, A., 2014. The pottery workshop area at piazza Nicola Amore, Naples. Black-glaze and common ware production: archaeology and archaeometry. In Archaeometry. comparing experiences, pp. 89-109.

Gonizzi Barsanti S., Remondino, F., Visintini, D., 2013. 3D surveying and modeling of archaeological sites - some critical issues. In ISPRS Annals of the Photogrammetry, Remote Sensing and Spatial Information Sciences, Vol. 2. XXIV International CIPA Symposium, Strasbourg, France, pp. 145-150 (www.researchgate.net/publication/274053007).

Guidi, F., Marchesi, M., Vianini, G., Ricci, P. C., Agnoletti, M., Rossi, A., 2017. Il progetto D12. Promuovere il rilievo 3D per stimolare la ricerca. In Archeomatica, n. 4, pp. 36-43.

Olcese, G., 2010. Le anfore greco-italiche di Ischia archeologia $e$ archeometria: artigianato ed economia nel Golfo di Napoli. Quasar, Roma.

Pugliese, L., 2014. Anfore greco-italiche neapolitane (IV-III secolo a.C.). Scienze e lettere, Fecit te. 